Research article

\title{
The relationships between urban parks, residents' physical activity, and mental health benefits: A case study from Beijing, China
}

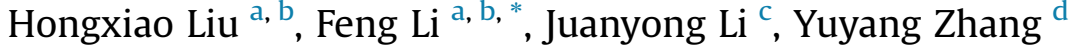 \\ a State Key Laboratory of Urban and Regional Ecology, Research Center for Eco-Environmental Sciences, Chinese Academy of Sciences, Beijing 100085, China \\ ${ }^{\mathrm{b}}$ University of Chinese Academy of Sciences, Beijing 100049, China \\ ${ }^{c}$ Hunan Agricultural University, China \\ d Beijing Institute of Water, Beijing 100048, China
}

\section{A R T I C L E I N F O}

\section{Article history:}

Received 22 March 2016

Received in revised form

18 December 2016

Accepted 23 December 2016

Available online 2 January 2017

\section{Keywords:}

Green space

Physical activity

Mental health benefits

Public health

Active lifestyle

\begin{abstract}
A B S T R A C T
The role of urban parks in improving public health has been analyzed in the context of urban design in developed countries, but has seldom been considered in developing countries such as China. Previous studies have found positive correlations between parks and residents' physical activity and mental health status. In this study, we conducted a questionnaire survey to investigate respondents' physical activity status and its relationship with urban parks. The impact of different activities engaged in during park use on positive mental health was examined.

The average physical activity level of the sample was 92.7 min of moderate to vigorous physical activity per day. Park users were more active in all forms of physical activity, except transport walking, than nonusers. The presence of a park within $500 \mathrm{~m}$ from home and park use were significantly associated with total physical activity. Physical activity in parks significantly restored visitors' moods and energy levels, and interaction with nature brought mental health benefits in terms of relaxation and self-perceived confidence. Overall, this study found a positive correlation of urban parks with public physical activity and positive mental health benefits. However, further research is needed to improve the understanding of this relationship in the context of China.
\end{abstract}

๑) 2016 Elsevier Ltd. All rights reserved.

\section{Introduction}

In metropolitan areas in China, the obesity rates in adults and children have reached $12.3 \%$ and $8.1 \%$, respectively; overweight adults accounted for $30 \%$ of the population (MHPRC et al., 2004). In addition to obesity, mental illness is also becoming a public concern (Chen and Qin, 2004). Lack of physical activity and unhealthy diet have been identified as primary causes of these public health problems (MHPRC et al., 2004). With the fast pace of urban life, many citizens fail to meet minimum standards for exercise (Cheng et al., 2007).

With rapid urbanization and socioeconomic development, people are increasingly deprived of access to nature as well as

Abbreviations: MVPA, moderate to vigorous physical activity; METs, Metabolic Equivalent of Tasks.

* Corresponding author. State Key Laboratory of Urban and Regional Ecology, Research Center for Eco-Environmental Sciences, Chinese Academy of Sciences, Beijing 100085, China.

E-mail address: lifeng@rcees.ac.cn (F. Li). physically inactive, which contribute to the above mentioned health problems (Louv, 2011; Godfrey and Julien, 2005; Dye, 2008). The role of different types of urban greenspace in promoting active lifestyles has been studied in developed countries. Greenspaces promote physical activity by providing free and readily accessible locations for active pastimes. A number of studies suggest that people who live in greener neighborhoods undertake more (and sometimes more vigorous) physical activity, such as cycling and walking (Andersen et al., 2015; Shanahan et al., 2015a). Although there is still controversy regarding the idea that greenspaces trigger physical activity or that active individuals are inclined to select places with more greenspace, many cities have incorporated the idea of increasing greenness in neighborhoods to encourage exercise (Church et al., 2014; Wolf and Wohlfart, 2014). For example, in the 100 largest cities in the US alone, over US \$6 billion was invested into the provision, management, and enhancement of public green spaces in 2015 (Shanahan et al., 2015a, 2015b). Additionally, a number of international organizations-such as the Centers for Disease Control and Prevention, the Institute of Medicine, and the World Health Organization-have identified urban 
environment design (e.g., walkable street design) as a promising way to improve residents' physical activity levels (Edwards and Tsouros, 2006). However, research from developing countries is still limited. People from different socioeconomic strata and cultural backgrounds perceive the environment differently, and their physical activity behaviors are constrained by different factors (Cohen et al., 2013; Harris et al., 2013; Gobster and Westphal, 2004). Therefore, it is important to conduct empirical study in developing countries to lay the groundwork for improving urban design to promote an active lifestyle.

The previous research framework discussing urban parks and mental health could be summarized into three mechanistic pathways: (1) The natural environment provides a view requiring less concentration or focus and does not stimulate a stress response (in an urban environment, people need to pay attention to cars, traffic lights, etc.); thus, simply being exposed to nature could improve cognitive functioning (Rogerson and Barton, 2015), offer restorative experiences (Kaplan and Kaplan, 1989), reduce mental stress (Ulrich et al., 1989), and promote recovery from attentional fatigue (Ball et al., 2006). (2) Urban greenspace provides free and comfortable accessible locations for physical activity. Physical activity in natural settings has a synergetic beneficial effect compared with that in artificial settings (Shanahan et al., 2016a, 2016b). (3) Urban greenspace also provides a forum for social contact among neighborhood residents, increasing social cohesion and place attachment (Deforche et al., 2010). Many studies have attempted to directly link visual, microclimate (Mitchell, 2013), aesthetic and accessibility (Irvine et al., 2013) characteristics of greenspace with greenspace use and mental health outcomes (Edwards et al., 2015). The impact of how people use greenspace (frequency, duration, use or no use of facilities, activity) on mental response is still not well understood. This is important because promoting public health requires not just building favorable greenspace, but promoting healthier behavior. Several studies had found different activities in parks (physical exercise, sightseeing, socializing, being outdoors, experiencing nature) had different impacts on health and wellbeing outcomes (Church et al., 2014; Wolf and Wohlfart, 2014). However, such evidence is still scarce. The present study attempted to link specific activities in parks with specific mental health outcomes in hopes of improving the understanding of urban greenspace use and its relationship with residents' mental response.

In this study, we investigated the role of urban parks in the promotion of physical activity and positive mental health after park use in Beijing, a typical rapidly urbanizing metropolis in China. Specifically, we sought to answer three questions: (1) Are the physical activity profiles of park users different from those of park non-users? (2) Among environmental and individual factors, which factors are significantly associated with physical activity? (3) How are different types of activities in parks associated with the mental health benefits derived from park use?

\section{Methods}

\subsection{Brief description of the city}

Beijing is a typical rapid urbanized area in China as well as one of the largest cities in the world, with a population of 19.6 million as of 2010. It is also one of the most densely populated metropolises in the world (7837 cap/ $/ \mathrm{km}^{2}$ ) (BMBS, 2011). In 2014, the amount of park land in Beijing reached 28,798 ha, or $15.7 \%$ of the total urban area, equal to $15.9 \mathrm{~m}^{2} / \mathrm{cap}$ (http://www.bjyl.gov.cn/zwgk/tjxx/). For comparison, the proportion of park land in both New York and Washington, D.C. is approximately $19 \%$ of the total urban area, equal to $18.6 \mathrm{~m}^{2}$ /cap and $52.2 \mathrm{~m}^{2} / \mathrm{cap}$, respectively (Liu et al., 2015).

\subsection{Social survey design and data collection}

This survey is part of a project called "The Modeling of Urban Ecological Infrastructure and Its Management and Regulation Methods," supported by the National Science Foundation of China, A cross-sectional, door-to-door, face-to-face survey was conducted around North 5th Ring Road (Fig. 1, S. 1) from June to September 2014. Protected forests had been converted into several urban parks prior to the 2008 Olympic Games. Because the purpose of this study was to test the effects of urban parks on public health, rather than conducting a city-level general survey, variabilities were minimized by conducting the survey in settings that were similar in many respects. A better picture might have emerged if surveys were conducted across the entire city, but this would require a larger

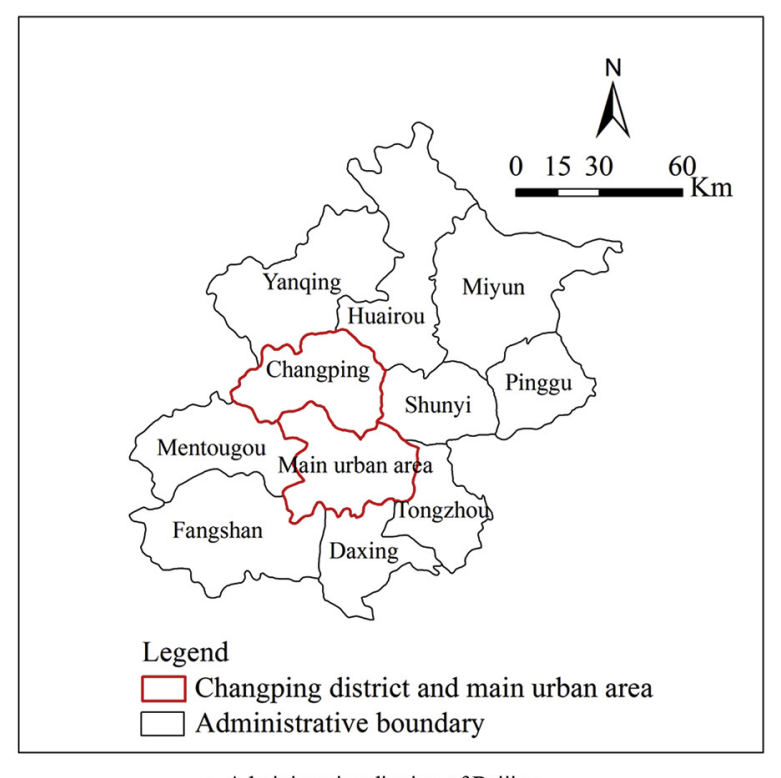

a. Administrative districts of Beijing.

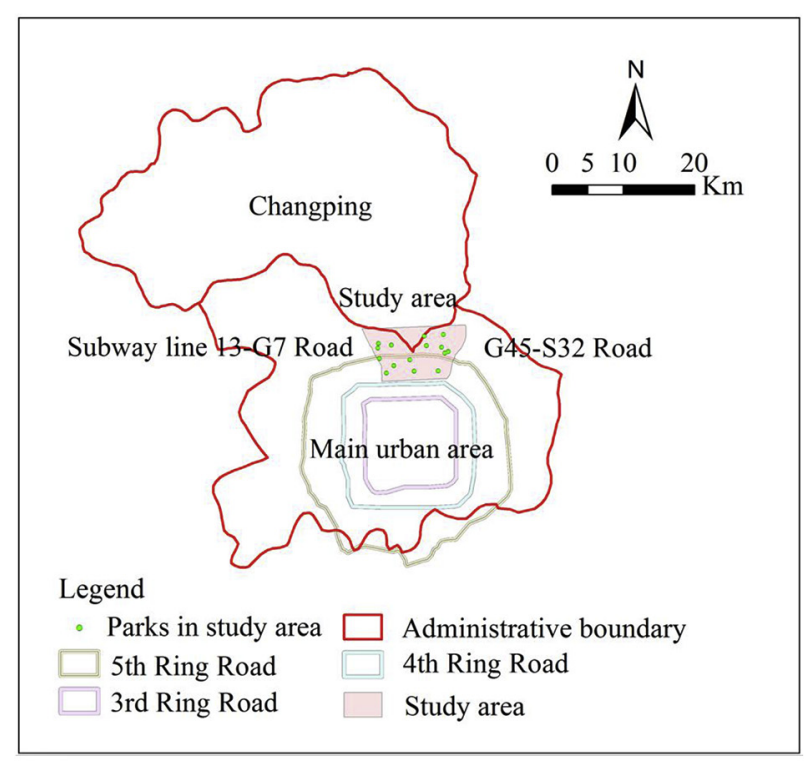

b. Detailed location of the study area.

Fig. 1. Location of the study area (Liu et al., 2015). a. Administrative districts of Beijing. b. Detailed location of the study area. 
sample size to represent the overall situation of the city, which was beyond the time and expenditure limitations of this project. The study area included various types of parks in an effort to improve the representativeness. The survey was conducted by trained staff. See Liu et al. (2015) for detailed description of the study design. Prior to data collection, a test sample of 30 questionnaires was used to determine whether the reading level, language, and format were appropriate for the residents. The questionnaire took an average of 20 min to complete (Liu et al., 2015). We randomly selected 50 residence communities in the study area, and our staff went to the communities and conducted the survey. The participants were selected randomly in each residence community. To increase the representativeness of the sample, we selected weekends and nonworking hours to conduct the survey, since retired or old people could be overrepresented on workdays during work hours.

\subsubsection{Physical activity profile measurement}

We assessed physical activity using the short form of the International Physical Activity Questionnaire (IPAQ), whose application in China has been validated (Qu and $\mathrm{Li}, 2004$; Li, 2004). The specific methods can be found in Craig et al. (2003). The questionnaire collects information on the time (i.e., number of days and average time per day) spent being physically active and measures vigorous-intensity activity, moderate-intensity activity, walking activity, and sitting in the past seven consecutive days. These activity categories may be treated separately to obtain specific activity patterns or multiplied by their estimated value in the Metabolic Equivalent of Tasks (METs) and summed to gain an overall estimate of physical activity in a week.

Consistent with the International Physical Activity Questionnaire, we added one more question to distinguish between transport walking (walking with the aim of getting to a destination) and fitness walking (walking with the aim of engaging in exercise) within total walking activity. In addition, the physical activity that occurred in residential greenspace was recorded using the same criteria as in the International Physical Activity Questionnaire method.

Because physical activity of different intensities (e.g., leisurely walking or hiking) has different impacts on human health, we converted different physical activities into moderate to vigorous physical activity (MVPA in minutes) for the purpose of comparison using the metabolic equivalent method suggested by the American College of Sports Medicine (ACSM) (Wolf and Wohlfart, 2014). This method calculates the metabolic equivalent burned during physical activity at certain intensity levels (S. Table 1). MET is an indicator of energy metabolism that indicates oxygen metabolism per minute per kilogram of body weight during physical activity. For example, for a middle-aged adult, the oxygen metabolism intensity of an hour's light physical activity is 2.0-3.9 METs, which is equivalent to 42 min of moderate physical activity. In this analysis, all outcome variables relating to physical activity were calculated in MVPA (minutes) by this method.

\subsubsection{Correlates of residents' physical activity}

The overview of measured items is shown in Table 4.

Socio-demographic variables (age, occupation, gender, income, and education level) were collected by questionnaire.

Environmental variables included characteristics of the residential community of the respondent and the park's accessibility to that community. Specifically, residential community characteristics included plot ratio, proportion of residential greenspace, and average housing price; these were obtained from the website of a real estate agency. Park accessibility variables included the number of parks within $500 \mathrm{~m}, 1000 \mathrm{~m}$, and $1500 \mathrm{~m}$ of the participant's home, and the number of turns along the optimized path from the participant's home to the nearest park; these were obtained through Gaode Map. The participant's address and perceived quality (accessibility, maintenance, aesthetic and comfort of the park) of the nearest park were collected by questionnaire.

Individual variables included leisure and work time on a typical weekday and on weekends, self-reported busyness, time spent in residential greenspace, park use (yes/no) in the past week, and personal attitude toward park visits. These parameters were collected by questionnaire. Personal attitude was measured using the tripartite model (Joshua et al., 2013). The tripartite model has been applied to various natural resource issues. For example, Bright and Manfredo (1996) employed the tripartite model to examine public attitudes toward wolf reintroduction. According to the model, three components-cognitive, affective, and behavioral-contribute to personal attitudes (Fig. 2). The cognitive contribution relates to the logical, reasoned, conscious, and purposeful evaluation of the attributes of a subject under an individual's consideration. The affective component relates to an individual's feelings about a subject and is typically considered more implicit or unmediated. The behavioral component is influential, given that recollected or related behaviors tend to be consistent with attitude (Joshua et al., 2013). Detailed information on the measurement of these factors can be found in our previous publication (Liu et al., 2015). A reliability test showed good internal consistency (Cronbach's alpha $=0.7$ ).

\subsubsection{Park visit survey}

Only participants who had visited parks (park users) in the past week filled out this part of survey. Participants were asked to record detailed information about their last visit, including the transportation mode they took to the park, time spent at the park, the specific activity they engaged in at the park, and the duration of each activity. We calculated the amount of physical activity they performed at the park according to International Physical Activity Questionnaire criteria. To understand the mental health benefits of different activity types, we grouped activities that occurred at the park as shown in S. Table 2. Activity diversity indicates the number of activities people participated in at the parks. Transport mode was classified as walking $=1$, bicycling $=2$, bus and/or subway $=3$, or private $\operatorname{car}=4$.

\subsubsection{Mental benefit survey}

The immediate self-reported mental health benefits after the last park visit in the past week, details of which were recorded in the above paragraph, were investigated. Previous studies developed tools for assessing long-term mental status, such as the General Health Questionnaire and Mental Health Inventory (Orgeta et al., 2013; Gascon et al., 2015). Because our study sought to investigate immediate mental improvement after park visits, these tools were not suitable. Two similar studies were found based on which we developed five items to measure immediate mental health benefits (Church et al., 2014; Wolf and Wohlfart, 2014). The

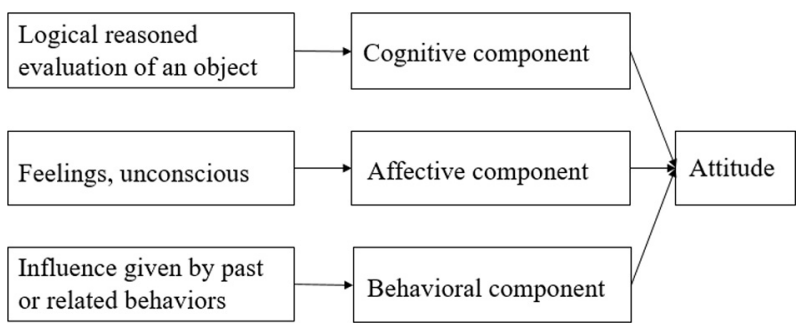

Fig. 2. The structure of tripartite model. 
items were answered using a scale from 0 to 100 , where 0 represented no improvement and 100 represented extreme improvement. The five items were: How would you rate the improvement in self-perceived health status after this park visit? How would you rate the improvement in self-perceived energy levels after this park visit?; How would you rate the improvement in self-perceived confidence after this park visit? To what extent do you feel this park visit relaxed you? To what extent do you feel this park visit restored your mood?

\subsection{Statistical analysis}

Data analysis was conducted using SPSS 18.0. The physical activity patterns of different socio-demographic groups were subjected to ANOVA. An independent sample $t$-test was used to compare the physical activity levels of park users and non-users.

Hierarchical regression analysis was used to investigate the association between total physical activity and socio-demographic, environmental, and individual factors and their relative importance. This model can be applied to collinear variables. In multiple regression analysis, the total variance explained by predicting variables can be divided into two parts: the unique contribution of each of the predicting variables and the overlapping contribution of the predicting variables (if multicollinearity exists). In traditional multiple regression analysis, the overlapping contribution is excluded from the semi-partial correlation of any predicting variables. Thus, the more the predicting variables overlap with each other, the smaller the semi-partial correlation of the variables will be. The semi-partial correlation of one predicting variable is related to other predicting variables if they are collinear. However, in hierarchical regression analysis, the overlapping effects are assigned to variables prior to entering them into the model so that the contribution and relative importance of backward-predicting variables can be distinguished. In the regression analysis, variables were divided into three blocks-socioeconomic demographic, environmental, and individual-and entered in the model successively. The exact independent variables in each block can be found in Table 4.

The correlates of mental health benefits and activity types were also subject to hierarchical regression analysis. Dependent variables were normalized if required and homogeneity of variance was verified before application of the regression model. Demographic factors (gender, age, occupation, income, education) were entered in the regression model first, then the other factors (amount of physical activity in the park, nature interaction, educational and cultural activity, etc.; see Table 5) were entered in the regression model. If the $\mathrm{R}^{2}$ of the model decreased with inclusion of an independent variable, the variable was excluded from the model.

\section{Results}

\subsection{Description of sample and overview of residents' physical activity}

We 308 questionnaires were valid; the rate was 38.5\%. A total of $48.5 \%$ of our participants were male, and $80.6 \%$ were young or middle-aged (20-40 years old); $77.1 \%$ of the participants had at least a college degree. Our survey revealed seven occupation types, including enterprise employees (39.3\%), institutional and government staff $(21.8 \%)$, and students (8.9\%). A total of $57 \%$ of the participants had an income between US $\$ 441$ and $\$ 1471$ per month. The average physical activity level of the sample was $92.7 \mathrm{~min}$ of MVPA per day, among which moderate physical activity, vigorous physical activity, transport walking, and leisure walking accounted for $9.7 \%$ ( $8.8 \mathrm{~min}$ ), 13.9\% (13.0 $\mathrm{min}$ ), $40.7 \%$ (41.6 $\mathrm{min}$ ), and $35.6 \%$ (29.8 $\mathrm{min})$, respectively (Table 1$)$.

\subsection{Physical activity profile comparison of park users and non- users}

As Table 2 shows, park users had 34.3 min more MVPA than nonusers. Park users also had significantly more physical activity in all forms except transport walking. Fitness walking, transport walking, vigorous activity, and moderate activity accounted for $34.7 \%, 38.5 \%$, $15.1 \%$, and $8.9 \%$ of total physical activity for park users and $24.8 \%$, $50.1 \%, 11.7 \%$, and $7.0 \%$ of total physical activity for non-users, respectively. On average, park users engaged in 27.4 min of MVPA per day during park use, accounting for $28.9 \%$ of their total physical activity. For park users, physical activity in residential greenspace accounted for a greater proportion of total physical activity than park-related physical activity (the sum of physical activity that occurred at the park and travelling to the park).

\subsection{Relative importance of factors related to residents' physical activity}

The results of the hierarchical regression analysis are shown in Tables 3 and 4. Socio-demographic variables alone explained only $1.7 \%$ of the total variance of the dependent variables (total physical activity, converted into MVPA) $(\mathrm{F}=2.0, \mathrm{P}=0.078)$. With the addition of environmental variables in the second step, the explained variability of residents' physical activity increased by $3.7 \%(\mathrm{~F}=2.0, \mathrm{P}=0.012)$. In the third step, individual variables were added, and the model's performance further increased by $17.1 \%$ $(\mathrm{F}=4.5 ; \mathrm{P}=0.000)$. The full model accounted for $22.5 \%$ of the total variance. In the full model, leisure time on the weekend, time spent in residential greenspace, and park use (individual factors) were significantly associated with physical activity. Among environmental variables, only the number of parks within $500 \mathrm{~m}$ was associated with physical activity.

\subsection{Improvement in mental health following park visits}

Park visits generated diverse positive mental responses. People reported the greatest improvements in self-confidence (69.9), followed by energy levels (61.4), self-perceived health (60.0), mood restoration (52.0) and relaxation (37.8) (S. Table 3).

Total physical activity was positively associated with improvements in energy levels and mood (Table 5). Interactions with nature were significantly associated with relaxation and self-confidence. Time spent at the park significantly correlated with self-reported health status, and transport mode $(1=$ walking, 2 = bicycling, 3 = public transport, or $4=$ private car) was associated with mood and energy levels.

\section{Discussion}

\subsection{Physical activity profile of the sample}

The American College of Sports Medicine recommends at least 150-250 min of MVPA per week to maintain and promote human health. The average physical activity of our sample exceeded this level. A higher proportion of residents (59.9\%) in Beijing were found to meet the recommendations for physical activity than had been found in other cities in China (Cheng et al., 2007), which may be partly due to the high prevalence of walking as a form of transport. People in Beijing spent an average of 92.7 min per day travelling between home and work. About $49.8 \%$ of Beijing citizens take public transportation, which allows them to walk and/or bicycle between transfers (http://bj.people.com.cn/n/2014/0723/c8284021749483.html). The daily exercise caused by commuting (transport walking) is 41 and 42.4 for park users and non-park users in 
Table 1

Demographic characteristics and the residents' physical activity (PA) profiles (minutes per day).

\begin{tabular}{|c|c|c|c|c|c|c|c|c|c|c|c|c|}
\hline Socio-demogr & aphic variables $(\mathrm{N}=308)$ & Percent (\%) & Total PA & $\mathrm{P}$ & Transport walking & $\mathrm{P}$ & Fitness walking & $\mathrm{P}$ & Vigorous PA & $P$ & Moderate PA & $\mathrm{P}$ \\
\hline \multirow[t]{2}{*}{ Gender } & Male & 48.5 & 89.3 & 0.724 & 38.2 & 0.224 & 28.4 & 0.683 & 15.2 & 0.203 & 7.6 & 0.294 \\
\hline & Female & 51.5 & 95.1 & & 44.4 & & 29.9 & & 10.9 & & 9.9 & \\
\hline \multirow[t]{5}{*}{ Age } & $11-20$ & 6.5 & 117.0 & 0.434 & 41.7 & 0.876 & 43.8 & 0.029 & 9.2 & 0.524 & 22.2 & 0.016 \\
\hline & $21-30$ & 46.8 & 91.5 & & 40.0 & & 26.9 & & 15.5 & & 9.1 & \\
\hline & $31-40$ & 33.8 & 85.0 & & 40.9 & & 27.0 & & 9.5 & & 7.7 & \\
\hline & $41-50$ & 12.3 & 101.6 & & 46.9 & & 35.0 & & 16.0 & & 3.8 & \\
\hline & $51-60$ & 0.7 & 109.3 & & 60.0 & & 45.0 & & 0.0 & & 4.3 & \\
\hline \multirow[t]{4}{*}{ Education } & Middle school & 8.9 & 134.6 & 0.001 & 64.5 & 0.019 & 44.6 & 0.015 & 12.0 & 0.742 & 13.5 & 0.600 \\
\hline & High school & 14.0 & 99.6 & & 39.2 & & 32.7 & & 18.0 & & 9.6 & \\
\hline & College & 54.9 & 84.6 & & 39.0 & & 26.0 & & 11.5 & & 8.1 & \\
\hline & Post graduate & 22.2 & 89.9 & & 39.4 & & 28.5 & & 13.8 & & 8.2 & \\
\hline \multirow[t]{7}{*}{ Occupation } & Enterprise Employee's & 39.3 & 93.7 & 0.727 & 43.1 & 0.658 & 28.5 & 0.487 & 13.8 & 0.325 & 8.4 & 0.422 \\
\hline & Institution and government staff & 21.8 & 81.7 & & 40.0 & & 27.9 & & 8.0 & & 5.8 & \\
\hline & Self-employed entrepreneur & 13.3 & 96.9 & & 32.8 & & 34.4 & & 19.9 & & 9.8 & \\
\hline & Freelancer & 10.2 & 87.6 & & 40.8 & & 29.3 & & 7.3 & & 10.1 & \\
\hline & Retiree & 3.8 & 108.7 & & 54.6 & & 24.6 & & 21.4 & & 8.2 & \\
\hline & Student & 8.9 & 108.7 & & 41.0 & & 33.3 & & 18.0 & & 16.3 & \\
\hline & Others & 2.7 & 76.0 & & 55.0 & & 15.0 & & 0.9 & & 5.2 & \\
\hline \multirow[t]{4}{*}{ Income (US\$) } & $<441$ & 25.6 & 102.2 & 0.562 & 48.5 & 0.293 & 28.7 & 0.914 & 13.6 & 0.525 & 11.5 & 0.142 \\
\hline & $441-882$ & 32.1 & 91.8 & & 38.2 & & 30.8 & & 12.2 & & 10.6 & \\
\hline & $882-1471$ & 24.9 & 86.2 & & 42.1 & & 28.1 & & 10.0 & & 6.1 & \\
\hline & $>1471$ & 17.4 & 87.2 & & 35.7 & & 28.3 & & 17.8 & & 5.3 & \\
\hline Total Mean & & & 92.7 & & 41.6 & & 29.3 & & 13.0 & & 8.8 & \\
\hline
\end{tabular}

Note: Physical activity was measured by moderate to vigorous physical activity (MVPA). The bold font indicate $\mathrm{P} \leq 0.05$.

Table 2

Physical activity (PA) profiles of park user and non-users (minutes).

\begin{tabular}{|c|c|c|c|c|c|c|}
\hline PA forms & Non-users $\mathrm{N}=185$ & Percent in total PA & Park users $\mathrm{N}=123$ & Percent in total PA & $\mathrm{t}$ & $\mathrm{P}$ \\
\hline PA in park & - & - & 22.8 & $23.9 \%$ & - & - \\
\hline PA travelling to park & - & - & 4.6 & $5.1 \%$ & - & - \\
\hline Park induced PA & - & - & 27.4 & $28.9 \%$ & - & - \\
\hline $\mathrm{PA}$ in $\mathrm{RG}$ & 23.1 & $41.0 \%$ & 44.7 & $43.2 \%$ & $-4.4^{* * *}$ & 0.000 \\
\hline Fitness walking & 22.3 & $24.8 \%$ & 39.0 & $34.8 \%$ & $-5.1^{* * *}$ & 0.000 \\
\hline Transport walking & 41.0 & $50.1 \%$ & 42.4 & $38.5 \%$ & -0.3 & 0.782 \\
\hline Vigorous PA & 9.2 & $11.7 \%$ & 18.4 & $15.1 \%$ & $-2.5^{*}$ & 0.012 \\
\hline Moderate PA & 6.8 & $7.0 \%$ & 11.9 & $8.9 \%$ & $-2.2^{*}$ & 0.027 \\
\hline Total PA & 79.8 & $100 \%$ & 111.1 & $100 \%$ & $-4.6^{* * *}$ & 0.000 \\
\hline
\end{tabular}

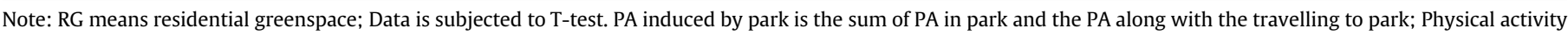
was measured by moderate to vigorous physical activity (MVPA). The bold font indicate $\mathrm{P} \leq 0.05$.

Table 3

Model performance of hierarchical multiple regression.

\begin{tabular}{lllll}
\hline Model & Adj. $\mathrm{R}^{2}$ & $\Delta$ Adj. $\mathrm{R}^{2}$ & $\mathrm{~F}$ & $\mathrm{P}$ \\
\hline 1 & $1.7 \%$ & & 2.0 & 0.078 \\
2 & $5.4 \%$ & $3.7 \%$ & 2.0 & $\mathbf{0 . 0 1 2}$ \\
3 & $22.5 \%$ & $17.1 \%$ & 4.5 & $\mathbf{0 . 0 0 0}$ \\
\hline
\end{tabular}

Model 1: Only socio-demographic variables entered the model; Model 2: Adding environmental variables based on Model 1; Model 3: Adding individual variables based on Model 2 . The bold font indicate $\mathrm{P} \leq 0.05$.

this study.

Park visits resulted in, on average, 27.4 min of MVPA per day (2-3 park visits per week, 68.3 min of MVPA per visit), accounting for $28.9 \%$ of total physical activity. Given the park usage levels observed in this study, park users are already meeting the recommended level of physical activity through their park visits alone. Park visits also have the potential to control obesity in the population. As reported by the American College of Sports Medicine, at 5.0 METs (moderate activity metabolism intensity for a $60-\mathrm{kg}$ adult), one visit to the park burns $355.1 \mathrm{kcal}$, equal to $39.5 \mathrm{~g}$ body fat.

\subsection{Comparison between park users and non-users}

Park users accounted for $39.9 \%$ of the sample. They exhibited higher physical activity levels in fitness walking, vigorous physical activity, moderate physical activity, and even physical activity in residence community greenspace, but not in transport walking. Previous research has revealed significant attitudinal differences between park users and non-users (Joshua et al., 2013). It is likely that park users are more active in nature, and that they therefore visit parks more frequently and engage in more physical activity. It is also possible that the presence of parks enables more activity and gradually cultivates people's physical activity habits. Although the causal relationship is still being developed, the finding that park users are more physically active than non-users has been confirmed by previous studies (McCormack et al., 2010; Joshua et al., 2013; Voigt et al., 2014).

\subsection{Relative importance of variables associated with total physical activity}

In this study, the effect sizes (st. $\beta$ ) of park use, time spent in residential greenspace, and leisure time on weekends were similar to but larger than other significant variables (education and park access within $0.5 \mathrm{~km}$, Table 4). The contributions of residential and public parks to residents' physical activity have been discussed in previous research. The State Sports Bureau of China surveyed 43,629 people from 10 provinces and found that $23.7 \%$ of people 
Table 4

The association of variables with residents' physical activity (PA) (MVPA in minutes).

\begin{tabular}{|c|c|c|c|c|c|c|c|}
\hline Variables & $\beta$ & St. $\beta$ & $\mathrm{P}$ & Variables & $\beta$ & St. $\beta$ & $\mathrm{P}$ \\
\hline Socioeconomic demographic variables & & & & Number of turns during route to nearest park & 0.2 & 0.1 & 0.314 \\
\hline Intercept & & & 0.007 & Number of parks within $0.5 \mathrm{~km}$ of home & $1.2^{*}$ & $0.1^{*}$ & 0.046 \\
\hline Gender & 0.009 & 0.01 & 0.820 & Number of parks within $1 \mathrm{~km}$ of home & 0.7 & 0.1 & 0.096 \\
\hline Age & -0.9 & -0.1 & 0.308 & Number of parks within $1.5 \mathrm{~km}$ of home & 0.5 & 0.1 & 0.051 \\
\hline Education & $-1.0^{*}$ & $-0.1^{*}$ & 0.017 & Perceived park quality & -0.3 & -0.1 & 0.064 \\
\hline Occupation & -0.3 & -0.1 & 0.378 & Individual variables & & & \\
\hline Income & -0.7 & -0.1 & 0.098 & Mean work time on weekdays & -0.2 & -0.1 & 0.471 \\
\hline Environmental variables & & & & Mean leisure time on weekdays & -0.009 & -0.01 & 0.93 \\
\hline plot ratio & -0.3 & -0.02 & 0.786 & Mean work time on weekends & 0.1 & 0.004 & 0.479 \\
\hline PRG & -7.7 & -0.1 & 0.183 & Mean leisure time on weekends & $0.6^{* * *}$ & $0.2^{* * *}$ & 0.000 \\
\hline Average housing price & 0.4 & 0.03 & 0.545 & Self-reported level of busyness & 0.2 & 0.003 & 0.657 \\
\hline Shortest road distance to nearest park & -0.3 & -0.1 & 0.170 & Time spent in RG & $0.4^{* * *}$ & $0.3^{* * *}$ & 0.000 \\
\hline Grade of shortest road distance to nearest park & -0.7 & -0.1 & 0.420 & Park use/no use & $3.2^{* * *}$ & $0.2^{* * *}$ & 0.000 \\
\hline Walking time to nearest park & -0.1 & -0.1 & 0.102 & Attitude to park visit & -1.6 & -0.002 & 0.817 \\
\hline
\end{tabular}

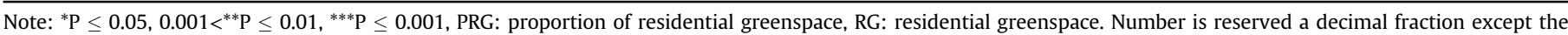
number is zero after reservation. The bold font indicate $\mathrm{P} \leq 0.05$.

Table 5

Effects of different types of activities in parks on mental health benefits.

\begin{tabular}{|c|c|c|c|c|c|c|c|c|c|c|}
\hline \multirow[t]{3}{*}{ Different types of activities } & \multicolumn{2}{|c|}{ Energy recharge } & \multicolumn{2}{|c|}{$\begin{array}{l}\text { Self-perceived } \\
\text { health }\end{array}$} & \multicolumn{2}{|c|}{ Mood restoration } & \multicolumn{2}{|c|}{$\begin{array}{l}\text { Self-perceived } \\
\text { confidence }\end{array}$} & \multicolumn{2}{|c|}{ Relaxation } \\
\hline & St. $\beta$ & $\mathrm{P}$ & St. $\beta$ & $\mathrm{P}$ & St. $\beta$ & $\mathrm{P}$ & St. $\beta$ & $\mathrm{P}$ & St. $\beta$ & $\mathrm{P}$ \\
\hline & \multicolumn{2}{|l|}{$\beta$} & \multicolumn{2}{|l|}{$\beta$} & \multicolumn{2}{|l|}{$\beta$} & \multicolumn{2}{|l|}{$\beta$} & \multicolumn{2}{|l|}{$\beta$} \\
\hline Intercept & & 0.263 & & 0.932 & & 0.012 & & 0.015 & & 0.781 \\
\hline Gender & $\begin{array}{l}-0.1 \\
-0.1\end{array}$ & 0.259 & $\begin{array}{l}-0.01 \\
-0.2\end{array}$ & 0.149 & $\begin{array}{l}-0.01 \\
-0.01\end{array}$ & 0.906 & $\begin{array}{l}0.03 \\
0.1\end{array}$ & 0.673 & $\begin{array}{l}-0.1 \\
-0.9\end{array}$ & 0.437 \\
\hline Age & $\begin{array}{l}0.01 \\
0.01\end{array}$ & 0.88 & $\begin{array}{l}0.04 \\
0.1\end{array}$ & 0.551 & $\begin{array}{l}0.1 \\
0.1\end{array}$ & 0.340 & $\begin{array}{l}0.2^{*} \\
0.2^{*}\end{array}$ & 0.029 & $\begin{array}{l}0.02 \\
0.02\end{array}$ & 0.82 \\
\hline Education & $\begin{array}{l}-0.1 \\
-0.1\end{array}$ & 0.406 & $\begin{array}{l}-0.04 \\
-0.04\end{array}$ & 0.575 & $\begin{array}{l}0.04 \\
0.1\end{array}$ & 0.499 & $\begin{array}{l}0.04 \\
0.04\end{array}$ & 0.606 & $\begin{array}{l}0.1 \\
0.1\end{array}$ & 0.282 \\
\hline Occupation & $\begin{array}{l}-0.1 \\
-0.03\end{array}$ & 0.101 & $\begin{array}{l}-0.04 \\
-0.02\end{array}$ & 0.577 & $\begin{array}{l}0.1^{*} \\
0.02^{*}\end{array}$ & 0.025 & $\begin{array}{l}0.04 \\
0.02\end{array}$ & 0.600 & $\begin{array}{l}0.1 \\
0.04\end{array}$ & 0.141 \\
\hline Income & $\begin{array}{l}-0.2^{* *} \\
-0.2^{* *}\end{array}$ & 0.004 & $\begin{array}{l}0.04 \\
0.03\end{array}$ & 0.62 & $\begin{array}{l}-0.1 \\
-0.1\end{array}$ & 0.177 & $\begin{array}{l}-0.01 \\
-0.01\end{array}$ & 0.942 & $\begin{array}{l}-0.1 \\
-0.1\end{array}$ & 0.129 \\
\hline Amount of PA in park & $\begin{array}{l}0.2^{* *} \\
0.03^{* *}\end{array}$ & 0.002 & $\begin{array}{l}0.1 \\
0.01\end{array}$ & 0.465 & $\begin{array}{l}0.4^{* * *} \\
0.1^{* * *}\end{array}$ & 0.000 & $\begin{array}{l}-0.04 \\
-0.01\end{array}$ & 0.573 & $\begin{array}{l}0.03 \\
0.001\end{array}$ & 0.722 \\
\hline Nature interaction & $\begin{array}{l}0.001 \\
0.003\end{array}$ & 0.980 & $\begin{array}{l}-0.1 \\
-0.1\end{array}$ & 0.502 & $\begin{array}{l}0.1 \\
0.1\end{array}$ & 0.261 & $\begin{array}{l}0.2^{* *} \\
0.4^{* *}\end{array}$ & 0.005 & $\begin{array}{l}0.4^{* * *} \\
0.6^{* * *}\end{array}$ & 0.000 \\
\hline Educational and cultural activity & $\begin{array}{l}0.1 \\
0.5\end{array}$ & 0.112 & $\begin{array}{l}0.03 \\
0.2\end{array}$ & 0.715 & $\begin{array}{l}0.1 \\
0.2\end{array}$ & 0.375 & $\begin{array}{l}-0.1 \\
-0.4\end{array}$ & 0.257 & $\begin{array}{l}-0.04 \\
-0.2\end{array}$ & 0.636 \\
\hline Social recreation & $\begin{array}{l}-0.03 \\
-0.1\end{array}$ & 0.671 & $\begin{array}{l}-0.02 \\
-0.1\end{array}$ & 0.77 & $\begin{array}{l}0.01 \\
0.01\end{array}$ & 0.942 & $\begin{array}{l}0.3^{* * * *} \\
0.4^{* * *}\end{array}$ & 0.001 & $\begin{array}{l}0.2 \\
0.4\end{array}$ & 0.059 \\
\hline Activity diversity & $\begin{array}{l}-0.1 \\
-0.1\end{array}$ & 0.513 & $\begin{array}{l}0.03 \\
0.04\end{array}$ & 0.737 & $\begin{array}{l}-0.01 \\
-0.01\end{array}$ & 0.929 & $\begin{array}{l}0.2^{* *} \\
0.3^{* *}\end{array}$ & 0.009 & $\begin{array}{l}0.1 \\
0.1\end{array}$ & 0.452 \\
\hline Transport mode & $\begin{array}{l}-0.2^{* *} \\
-0.2^{* *}\end{array}$ & 0.002 & $\begin{array}{l}-0.1 \\
-0.1\end{array}$ & 0.152 & $\begin{array}{l}0.2^{* * *} \\
0.2^{* * *}\end{array}$ & 0.000 & $\begin{array}{l}0.04 \\
0.03\end{array}$ & 0.573 & -0.1 & 0.518 \\
\hline Time duration in park & - & - & $\begin{array}{l}0.5^{* * *} \\
0.01^{* * *}\end{array}$ & 0.000 & - & - & - & - & $\begin{array}{l}-0.1 \\
-0.001\end{array}$ & 0.352 \\
\hline $\begin{array}{l}\mathrm{F} \\
\text { Adj } R^{2}\end{array}$ & $\begin{array}{l}4.0 \\
17.0 \%\end{array}$ & 0.000 & $\begin{array}{l}6.4 \\
27.0 \%\end{array}$ & 0.000 & $\begin{array}{l}7.9 \\
25.0 \%\end{array}$ & 0.000 & $\begin{array}{l}2.1 \\
5.0 \%\end{array}$ & 0.991 & $\begin{array}{l}3.7 \\
15.0 \%\end{array}$ & 0.000 \\
\hline
\end{tabular}

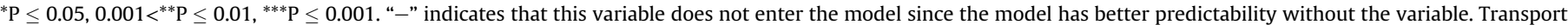

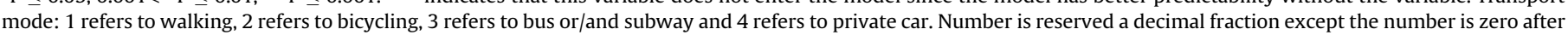
reservation. The bold font indicate $\mathrm{P} \leq 0.05$.

chose sports venues in their communities and workplaces as their favorite places to exercise, and $10.9 \%$ people engaged in physical activity at public parks (http://sports.163.com/13/0808/08/ 95097LI30005227R.html). Residential greenspace was more accessible and generally equipped with physical activity facilities, especially for older people, parents with young children, and the disabled. Residential greenspace also provides an opportunity for neighbors to communicate with each other. Public parks have more diverse landscapes and large areas of natural settings. Our study showed that the two forms of greenspace were both significantly correlated with physical activity; thus, they should be properly configured to meet residents' needs for recreation and physical activity.

Time limitations were reported as a common constraint on park use and physical activity, but they are seldom addressed in quantitative analysis. This constraint could be mitigated by building more accessible greenspaces (greenspaces in workplaces or residential communities) and physical activity facilities. Interventions to improve residents' physical activity awareness and self-efficacy are also important because time limitations are often related to physical activity being a low priority. 


\subsection{Associations of different activities in parks with mental health outcomes}

Among the four types of activities (physical activity in parks, interactions with nature, educational and cultural activities, and social recreation), engaging in physical activity and nature interaction in parks made the greatest contribution to improving mental health compared with other activities, based on the number of associated mental health benefits. Similarly, Church et al. (2014) reported that physical activity in public open space brought more enjoyment than sedentary activities, but natural interaction made a greater improvement in terms of relaxation and revitalization. However, other studies have produced different results. One study found that the type, intensity, and duration of greenspace exercise had no effect on self-esteem and mood (Pretty et al., 2007). There are two possible reasons for this inconsistency. One is that people with different cultural, economic, and social status seek different benefits and respond differently to natural experience. Another possible reason is the subjectivity of mental benefit measurement. For example, in Church's et al. (2014) study, residents' perceptions of relaxation, enjoyment, and revitalization after park use were measured. Wolf and Wohlfart (2014) measured the levels of health and well-being improvements after park use. To residents, perceptions of relaxation, enjoyment, revitalization and well-being improvements are ambiguous and subjective. In future research, more robust psychological measurement or objective measurement of people's mental response could help clarify the mechanistic pathway of the benefits of green experience.

\subsection{Limitations}

Several limitations should be acknowledged and addressed in future research. (1) This study was based on a cross-sectional experimental design, which is unable to address the "self-selection" issue or to establish causal relationships. People who have relocated or neighborhoods with new parks provide opportunities to examine the self-selection issue. Comparative studies of individuals' preferences for physical activity, parks, and the physical activity behavior of people who have different levels of access to parks would help to clarify the causality between physical activity and parks. (2) Although the International Physical Activity Questionnaire is widely used in large population-based studies, its accuracy requires improvement due to its subjectivity. Innovative measurement technologies such as physical activity sensors (e.g., pedometers, accelerometers) with global positioning system technologies and wearable cameras should be used to provide robust evidence of how parks shape residents' physical activity. (3) The representativeness of the study would be improved if the sample size of the study were larger. However, it is difficult for environmental scholars to conduct such large-scale social investigations. Cooperation between the public health and environmental sectors, as well as data sharing, are important for improving our understanding of the environment and public health, which will help foster healthier lifestyles.

\section{Conclusion}

Although the association between urban greenspace and residents' physical activity has been studied extensively in developed countries, it is unclear whether such findings are applicable to China without conducting empirical studies. In this study, the roles of urban parks in improving physical activity and mental health were investigated. The main conclusions can be summarized as follows: (1) Park users are more active than park non-users in every form of physical activity except transport waking. (2) Park accessibility and park use were significantly correlated with residents' physical activity. (3) Physical activity and nature interaction in parks were significantly correlated with multiple mental health benefits. In sum, positive correlations were found between park accessibility as well as park use and residents' physical activity and mental health.

\section{Acknowledgments}

This research was funded by the National Natural Science Foundation of China (No. 71273254; 71533004; 71561137002) and National Key Research and Development Program (Grant No. 2016YFC0502804). We thank Zhang Zeyang, Xu Chongqi and Yao Liang for their contributions on the questionnaire survey and manuscript revision. We thank the reviewers for their constructive comments which improve the quality of this research.

\section{Appendix A. Supplementary data}

Supplementary data related to this article can be found at http:// dx.doi.org/10.1016/j.jenvman.2016.12.058.

\section{References}

Andersen, L., Gustat, J., Becker, A.B., 2015. The relationship between the social environment and lifestyle-related physical activity in a low-income African American inner-city Southern neighborhood. J. Community Health 40, 967-974.

Ball, K., Timperio, A.F., Crawford, D.A., 2006. Understanding environmental influences on nutrition and physical activity behaviors: where should we look and what should we count? Int. J. Behav. Nutr. Phys. Act. 3, 33-33.

BMBS, 2011. Beijing Statistical Yearbook 2011. China Statistics Press, Beijing, China. Bright, A.D., Manfredo, M.J., 1996. A conceptual model of attitudes toward natural resource issues: a case study of wolf reintroduction. Hum. Dimens. Wildl. 1, $1-21$.

Chen, C., Qin, Q., 2004. A research on the impact of urbanization on the residents' social behavior. Psychol. Sci. 27, 325-328.

Cheng, J., Zhao, D., Zeng, Z., Sun, J., Wang, M., Li, Y., 2007. Analysis on current status of physical activity among residents in Beijing. Chin. J. Public Health 5.

Church, A., Fish, R., Haines-Young, R., Mourato, S., Tratalos, J., 2014. UK National Ecosystem Assessment Follow-on. Work Package Report 5: Cultural Ecosystem Services and Indicators. UNEP-WCMC, LWEC, UK.

Cohen, D.A., Han, B., Derose, K., Williamson, P.S., Marsh, T., McKenzie, T.L., 2013. Physical activity in parks: a randomized controlled trial using community engagement. Am. J. Prev. Med. 45, 590-597.

Craig, C.L., Marshall, A.L., Sjostrom, M., Bauman, A.E., Booth, M.L., Ainsworth, B.E. Pratt, M., Ekelund, U., Yngve, A., Sallis, J.F., Oja, P., 2003. International physical activity questionnaire: 12-country reliability and validity. Med. Sci. Sports Exerc. 35, 1381-1395.

Deforche, B., Van Dyck, D., Verloigne, M., De Bourdeaudhuij, I., 2010. Perceived social and physical environmental correlates of physical activity in older adolescents and the moderating effect of self-efficacy. Prev. Med. 50 (Suppl. 1), S24-S29.

Dye, C., 2008. Health and urban living. Science 319, 766-769.

Edwards, N., Hooper, P., Knuiman, M., Foster, S., Giles-Corti, B., 2015. Associations between park features and adolescent park use for physical activity. Int. J. Behav. Nutr. Phys. Act. 12, 178-178.

Edwards, P., Tsouros, A., 2006. Promoting Physical Activity and Active Living in Urban Environments: the Role of Local Governments, the Solid Facts. WHO Regional Office for Europe.

Gascon, M., Triguero-Mas, M., Martinez, D., Dadvand, P., Forns, J., Plasencia, A., Nieuwenhuijsen, M.J., 2015. Mental health benefits of long-term exposure to residential green and blue spaces: a systematic review. Int. J. Environ. Res. Public Health 12, 4354-4379.

Godfrey, R., Julien, M., 2005. Urbanization and health. Clin. Med. 5 (2), 137-141.

Gobster, P.H., Westphal, L.M., 2004. The human dimensions of urban greenways: planning for recreation and related experiences. Landsc. Urban Plan. 68, $147-165$.

Harris, J.K., Lecy, J., Hipp, J.A., Brownson, R.C., Parra, D.C., 2013. Mapping the development of research on physical activity and the built environment. Prev. Med. 57, 533-540.

Irvine, K.N., Warber, S.L., Devine-Wright, P., Gaston, K.J., 2013. Understanding urban green space as a health resource: a qualitative comparison of visit motivation and derived effects among park users in Sheffield, UK. Int. J. Environ. Res. Public Health $10,417-442$.

Joshua, W.R.B., Tynon, J.F., Gómezc, E., 2013. Attitudes about urban nature parks: a case study of users and nonusers in Portland, Oregon. Landsc. Urban Plan. 117, 
$100-111$.

Kaplan, R., Kaplan, S., 1989. The Experience of Nature: a Psychological Perspective. Cambridge University Press, Cambridge, UK.

Li, Y., 2004. Residents' Physical Activity Evaluation in Shanghai. Doctoral Dissertation. Fudan University.

Liu, H.X., Li, F., Xu, L.F., Han, B.L., 2015. The relative influence of socio-demographic, environmental, and individual factors on urban park visitation among residents in Beijing, China. J. Clean. Prod. http://dx.doi.org/10.1016/j.jclepro.2015.09.012.

Louv, R., 2011. The Nature Principle: Human Restoration and the End of Naturedeficit Disorder. Algonquin Books.

MHPRC (Ministry of Health of the People's Republic of China), MSTPRC (Ministry of Science and Technology of the People's Republic of China), NBSPRC (The National Bureau of Statistics of the People's Republic of China), 2004. Nutrition and Health Status of Chinese Residents.

McCormack, G.R., Rock, M., Toohey, A.M., Hignell, D., 2010. Characteristics of urban parks associated with park use and physical activity: a review of qualitative research. Health \& Place 16, 712-726.

Mitchell, R., 2013. Is physical activity in natural environments better for mental health than physical activity in other environments? Soc. Sci. Med. 91, 130-134.

Orgeta, V., Lo Sterzo, E., Orrell, M., 2013. Assessing mental well-being in family carers of people with dementia using the Warwick-Edinburgh Mental WellBeing Scale. Int. Psychogeriatr. 25, 1443-1451.

Pretty, J., Peacock, J., Hine, R., Sellens, M., South, N., Griffin, M., 2007. Green exercise in the UK countryside: effects on health and psychological well-being, and implications for policy and planning. J. Environ. Plan. Manag. 50, 211-231.

Qu, N.N., Li, K.J., 2004. The reliability and validity test of the Chinese version of international physical activity questionnaire. Chin. J. Epidemiol. 2004 (03), 87-90.

Rogerson, M., Barton, J., 2015. Effects of the visual exercise environments on cognitive directed attention, energy expenditure and perceived exertion. Int. J.
Environ. Res. Public Health 12, 7321-7336.

Shanahan, D.F., Bush, R., Gaston, K.J., Lin, B.B., Dean, J., Barber, E., Fuller, R.A., 2016a Health benefits from nature experiences depend on dose. Nat. Rep. http:// dx.doi.org/10.1038/srep28551.

Shanahan, D.F., Franco, L., Lin, B.B., Gaston, K.J., Fuller, R.A., 2016b. The benefits of natural environments for physical activity. Sports Med. http://dx.doi.org/ 10.1007/s40279-016-0502-4.

Shanahan, D.F., Fuller, R.A., Bush, R., Lin, B.B., Gaston, K.J., 2015a. The health benefits of urban nature: how much do we need? BioScience 65, 476-485.

Shanahan, D.F., Lin, B.B., Bush, R., Gaston, K.J., Dean, J.H., Barber, E., Fuller, R.A. 2015b. Toward improved public health outcomes from urban nature. Toward improved public health outcomes from urban nature. Am. J. Public Health 105 (3), 470-477.

Ulrich, R.S., Simons, R.F., Losito, B.D., Fiorito, E., Miles, M.A., Michael, Z., 1989. Stress recovery during exposure to natural and urban environments. J. Environ. Psychol. 11 (3), 201-230.

Voigt, A., Kabisch, N., Wurster, D., Haase, D., Breuste, J., 2014. Structural diversity: a multi-dimensional Approach to assess recreational services in urban parks. Ambio 43, 480-491.

Wolf, I.D.W., Wohlfart, T., 2014. Walking, hiking and running in parks: a multidisciplinary assessment of health and well-being benefits. Landsc. Urban Plan. 130 89-103.

\section{Web reference}

http://sports.163.com/13/0808/08/95097LI30005227R.html. http://www.bjyl.gov.cn/zwgk/tjxx/.

http://bj.people.com.cn/n/2014/0723/c82840-21749483.html. 